ARTICLE

\title{
Biomineral armor in leaf-cutter ants
}

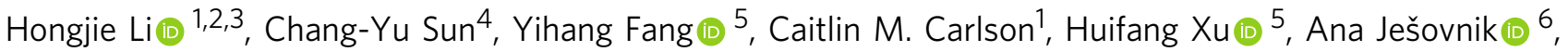 \\ Jeffrey Sosa-Calvo (1) 6,7, Robert Zarnowski (10 8,9, Hans A. Bechtel ${ }^{10}$, John H. Fournelle ${ }^{5}$, David R. Andes ${ }^{8,9}$, \\ Ted R. Schultz ${ }^{6}$, Pupa U. P. A. Gilbert (10) ${ }^{4,5,11 凶} \&$ Cameron R. Currie (i) ${ }^{1,2 \bowtie}$
}

Although calcareous anatomical structures have evolved in diverse animal groups, such structures have been unknown in insects. Here, we report the discovery of high-magnesium calcite $\left[\mathrm{CaMg}\left(\mathrm{CO}_{3}\right)_{2}\right]$ armor overlaying the exoskeletons of major workers of the leaf-cutter ant Acromyrmex echinatior. Live-rearing and in vitro synthesis experiments indicate that the biomineral layer accumulates rapidly as ant workers mature, that the layer is continuously distributed, covering nearly the entire integument, and that the ant epicuticle catalyzes biomineral nucleation and growth. In situ nanoindentation demonstrates that the biomineral layer significantly hardens the exoskeleton. Increased survival of ant workers with biomineralized exoskeletons during aggressive encounters with other ants and reduced infection by entomopathogenic fungi demonstrate the protective role of the biomineral layer. The discovery of biogenic high-magnesium calcite in the relatively well-studied leaf-cutting ants suggests that calcareous biominerals enriched in magnesium may be more common in metazoans than previously recognized.

\footnotetext{
${ }^{1}$ Department of Bacteriology, University of Wisconsin-Madison, Madison, WI 53706, USA. ${ }^{2}$ Department of Energy Great Lakes Bioenergy Research Center, Wisconsin Energy Institute, University of Wisconsin-Madison, Madison, WI 53726, USA. ${ }^{3}$ State Key Laboratory for Managing Biotic and Chemical Threats to the Quality and Safety of Agro-products, Key Laboratory of Biotechnology in Plant Protection of Ministry of Agriculture and Zhejiang Province, Institute of Plant Virology, Ningbo University, 315211 Ningbo, China. ${ }^{4}$ Department of Physics, University of Wisconsin-Madison, Madison, WI 53706, USA. ${ }^{5}$ Department of Geoscience, University of Wisconsin-Madison, Madison, WI 53706, USA. ${ }^{6}$ Department of Entomology, National Museum of Natural History, Smithsonian Institution, Washington, DC 20560-0003, USA. ${ }^{7}$ School of Life Sciences, Arizona State University, Tempe, AZ 85287, USA. ${ }^{8}$ Department of Medicine, University of Wisconsin-Madison, Madison, WI 53706, USA. ${ }^{9}$ Department of Medical Microbiology and Immunology, University of Wisconsin-Madison, Madison, WI 53706, USA. ${ }^{10}$ Advanced Light Source Division, Lawrence Berkeley National Laboratory, Berkeley, CA 94720, USA. ${ }^{11}$ Departments of Chemistry, Materials Science and Engineering, University of Wisconsin-Madison, Madison, WI 53706, USA. Previously published as

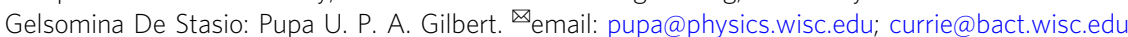


B iomineral skeletons first appeared more than 550 million years ago ${ }^{1-5}$, and by the early Cambrian biomineral-based defensive structures had evolved in most extant metazoan phyla, apparently in response to increasing predation pressure ${ }^{6}$. The minerals involved, as well as the biogenic structures they form, are diverse. Calcium carbonate biomineralization is particularly widespread among metazoans ${ }^{1,7}$ : the hard parts of corals ${ }^{8}$, mollusk shells ${ }^{9}$, stomatopod dactyl club ${ }^{10}$, and sea urchin spines $^{11}$ contain calcium carbonate, as do the light-focusing eye lenses of chitons and brittlestars ${ }^{12,13}$. Magnesium-enriched calcite $\left(\mathrm{CaCO}_{3}\right)$ has been discovered in the central part of the sea urchin tooth, where the increased hardness imparted by magnesium is thought to aid in the grinding of limestone ${ }^{14-16}$. Given the importance of calcareous anatomical structures across metazoan phyla and given that magnesium significantly strengthens such structures ${ }^{17}$, it is surprising that high-magnesium calcite appears to be rare in animals ${ }^{18}$. It is also surprising that despite the near ubiquity of biogenic mineralization across metazoan phyla and the widespread presence of calcium carbonate in the Crustacea, biomineralized calcium carbonate has so far remained unknown in the most diverse group of animals, the insects, which arose from within the Crustacea ${ }^{19}$. Here we report the discovery of a dense layer of biogenic high-magnesium calcite in the leaf-cutter ant Acromyrmex echinatior.

Fungus-growing attine ants (tribe Attini, subtribe Attina) engage in an ancient and obligate mutualism with coevolved fungi (order Agaricales), which they cultivate for food. Fungus farming, which has been described as a major transition in evolution ${ }^{20}$, evolved only once in ants around 60 million years $\mathrm{ago}^{20}$. Leafcutting ants (genera Acromyrmex and Atta), a phylogenetically derived lineage that arose within the fungus-growing ants around 20 million years ago, harvest fresh vegetation as the substrate on which they grow their fungal mutualists. They are ecologically dominant herbivores in the New World tropics ${ }^{20,21}$ and serve important roles in carbon and nitrogen cycling ${ }^{22}$. A mature Atta leaf-cutter ant colony comprises a superorganism with $>5$ million workers, a single queen, and complex society with a highly refined division of labor based both on worker size and age. Acromyrmex leaf-cutter colonies vary in size, generally within the range of $15,000-100,000$ workers $^{23,24}$, and in some species may have more than one queen. Acromyrmex echinatior, the focus of the present study, has a mean colony size of 137,500 workers and is facultatively polygynous 25,26 . In addition to the leaf-cutters, 17 other genera of ants occur within the Attina, all of which grow fungus gardens, form colonies of hundreds to a few thousand workers, and use dead vegetative matter or caterpillar frass rather than fresh leaves and grasses as substrates for their gardens. In addition to the symbiotic association with their fungal cultivars, many fungus-growing ants engage in a second mutualism with Actinobacteria (genus Pseudonocardia), which produce antibiotics that help defend the garden from fungal pathogen $s^{27-29}$. Fungusgrowing ant colonies, containing both fungal crops and immature ant brood, represent a rich nutritional resource for a wide variety of marauding ant species, including army ants and other known agro-predatory raiders of ant agriculture ${ }^{30}$. Smaller fungusgrowing ant colonies, including those of Acromyrmex, are also occasionally subject to attack by the large-sized soldier castes of Atta leaf-cutter ants, which use their powerful zinc-enriched mandibles to defend their colonies' territories against other, encroaching ant species ${ }^{31-33}$.

Many species of fungus-growing ants are variably covered with a whitish granular coating, uniformly distributed on their otherwise dark brown cuticles ${ }^{34}$, including, in addition to Acromyrmex echinatior (Fig. 1a), some species of Trachymyrmex and Sericomyrmex.

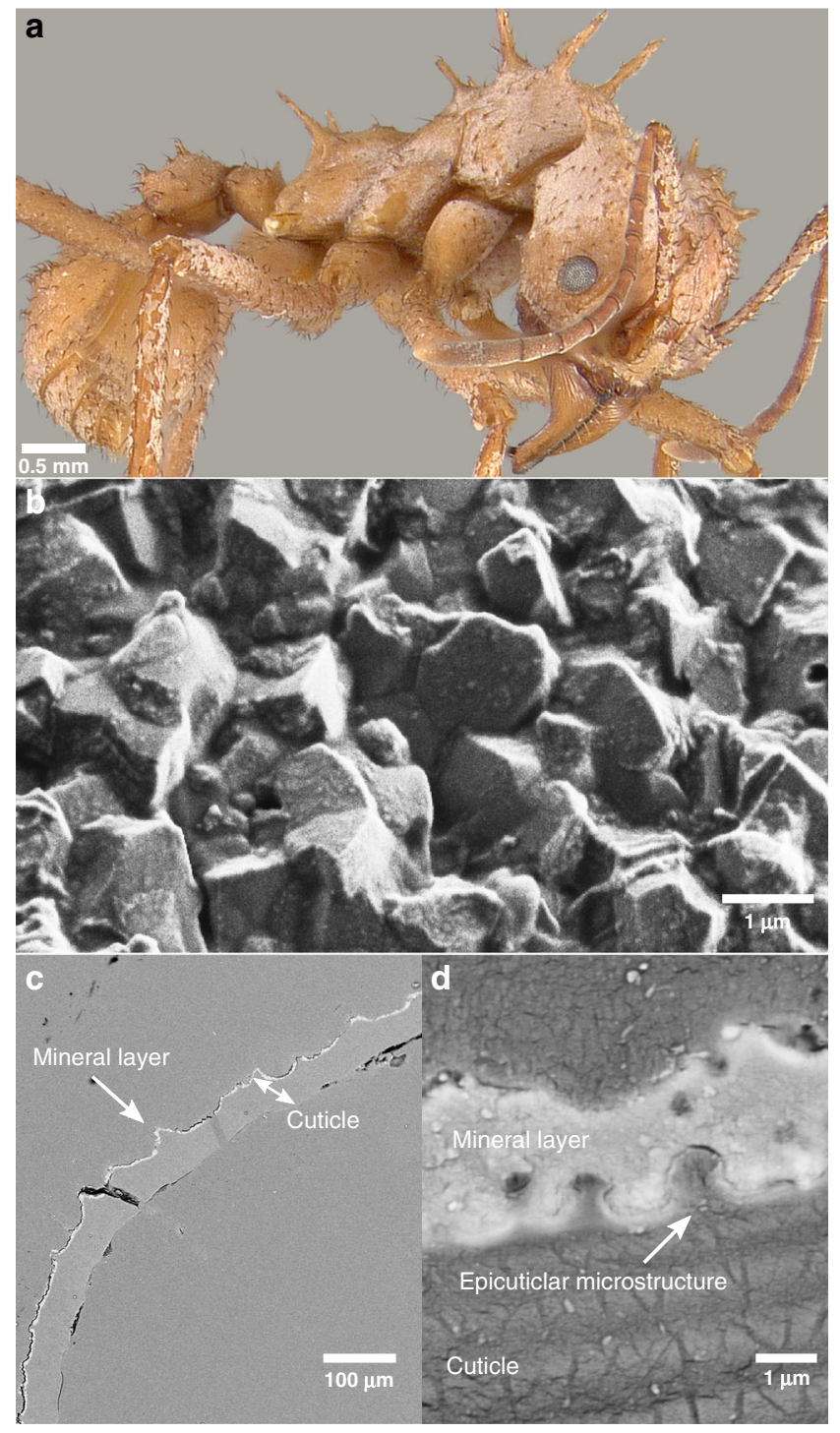

Fig. 1 Morphological and structural characterization of minerals on the cuticle of Ac. echinatior. a Ac. echinatior ant with a whitish cuticular coating (Photo T.R.S.). b SEM image of ant cuticle with crystalline coating.

c Backscattered electron (BSE) image of a polished cuticular cross-section of an ant. This layer is brighter than the cuticle in backscattered electron (BSE) mode scanning electron microscopy (SEM), indicating that it consists of heavier elements and is continuous, covering nearly the entire surface. d BSE image close-up of a polished cuticular cross-section of an ant.

Based on combined data from in situ X-ray diffraction (XRD), electron microscopy, electron backscatter diffraction (EBSD), quantitative electron probe micro-analysis (EPMA), and Raman and attenuated total reflectance Fourier-transform infrared (ATR-FTIR) spectroscopy, we report here that this coating is in fact a mineral layer covering the ant exoskeleton. The layer is composed of euhedral rhombohedral crystals with curved faces, 3-5 $\mu \mathrm{m}$ in size (Fig. 1b). To examine the mechanism of crystal growth, we conducted synchrotron X-ray PhotoEmission electron spectro-microscopy (X-PEEM), in vitro synthesis, and in vivo observation of crystallization and growth in an ant-rearing experiment. We measure the cuticle hardness of Ac. echinatior ants with and without the cuticular layer using in situ nanoindentation and explore two of several possible benefits associated with the biomineral armor in experimental ant battles and infections by entomopathogenic fungi. 


\section{Results}

Morphological, structural, and chemical characteristics of epicuticular minerals. Microscopic imaging of polished cuticular cross-sections of the leaf-cutting ant Acromyrmex echinatior reveals a clear interface between the crystalline layer and the ant cuticle (Fig. 1c). This layer is brighter than the cuticle in backscattered electron (BSE) mode scanning electron microscopy (SEM) (Fig. 1c, d), indicating that it consists of heavier elements and that it is continuously distributed, covering nearly the entire integumental surface. Energy-dispersive X-ray spectroscopy (EDS) characterization of the cuticular coating further indicates that the crystalline layer contains significant amounts of magnesium and calcium (Supplementary Fig. 1a-f), suggestive of an Mg-bearing calcite biomineral. XRD analysis confirms the highmagnesium calcite composition of the biomineral layer in $A c$. echinatior, as indicated by the $d$-spacing of (104) peak at $2.939 \AA$ (Fig. 2a and Supplementary Table 1). Quantitative electron probe micro-analysis (EPMA) reveals a magnesium concentration of $32.9 \pm 2.7 \mathrm{~mol} \%$ (Supplementary Table 2). Using bright-field transmission electron microscopy (TEM), selected area electron diffraction (SAED), TEM-EDS, and Raman and Attenuated Total Reflectance Fourier-Transform InfraRed (ATR-FTIR) spectra, we further confirmed that the biomineral is high-magnesium calcite with chemically heterogeneous crystals and with no observable $\mathrm{Ca}-\mathrm{Mg}$ ordering (i.e., no evidence for dolomite, the only $\mathrm{Ca}-\mathrm{Mg}$ carbonate phase with cation ordering) (Supplementary Figs. 2 and 3). Extensive XRD analyses of Ac. echinatior, including both lab-reared and field-collected workers from Panama and Brazil, confirms the consistent presence of high-magnesium calcite in quantities of $23-35 \mathrm{~mol} \% \mathrm{MgCO}_{3}$ (Supplementary Tables 2 and $3)$. To investigate the presence of amorphous calcium carbonate within the biomineral cuticular layer, we heat-treated or irradiated biomineral-bearing ants, and acquired XRD and TEMSAED data before and after either treatment. We did not find evidence of increased crystallinity in either the heat or radiation treatments in either X-ray or electron diffraction.

The mineral-cuticle interface of Acromyrmex echinatior was investigated using X-PEEM at the Advanced Light Source (Lawrence Berkeley National Laboratory, Berkeley, CA) (Fig. 2b) ${ }^{35}$. Distinct X-ray absorption near-edge structure (XANES) spectra occur at the carbon K-edge for each of three regions: cuticle, epicuticle, and mineral layer (Fig. 2c; mapped as spectral components ${ }^{8}$ in Fig. 2d). The $\mathrm{C}$ spectra for the mineral layer show a strong carbonate peak at $290.3 \mathrm{eV}$ (Fig. 2c). The oxygen K-edge spectra extracted from the ant mineral layer indicate that the carbonate crystals are crystalline with a strong crystal orientation dependence of peak 1 at $534 \mathrm{eV}$ (Fig. 2e). Polarization-dependent imaging contrast (PIC) mapping 36,37 across the mineral layer, in which color quantitatively displays the orientation of the crystal $c$-axes, indicates that crystals are randomly oriented (Fig. 2f, g; Fig. $2 \mathrm{f}$ magnifies images of Fig. $2 \mathrm{~g}$ ). The width of peak 2 in all $\mathrm{O}$ spectra (Fig. 2e) indicates a mixture of phases with high- and low-Mg concentrations ${ }^{17}$. This chemical heterogeneity is consistent with the XRD data (Fig. 2a), with electron microprobe analyses (Supplementary Table 2), with backscatter diffraction (EBSD) results (Supplementary Fig. 4), and with the magnified PIC map regions (Fig. 2f).

Unlike the typical chitin spectrum of insect epicuticle, the Acromyrmex echinatior XANES epicuticle spectrum is consistent with a protein-enriched insect epicuticle ${ }^{38}$. Protein hydrolysis of the cuticular layers verifies that the epicuticle is proteinaceous (Supplementary Fig. 5). Furthermore, the epicuticle spectrum shows a very intense peak at $285.2 \mathrm{eV}$ (Fig. 2c), which, based on its energy position and its symmetric line shape, suggests that the epicuticle contains one or more phenylalanine (Phe) enriched proteins $^{39}$. High-performance liquid chromatography (HPLC) amino acid profiling of the protein layer of the Ac. echinatior epicuticle confirms the presence of phenylalanine in the ant cuticle (Supplementary Table 4).

In vitro high-Mg calcite synthesis. To assess whether epicuticular proteins mediate the precipitation of high-magnesium calcite in Acromyrmex echinatior, we performed synthetic biomineralization experiments in which the cuticle of Ac. echinatior was incubated in saturated carbonate solutions with a $\left[\mathrm{Mg}^{2+}\right] /\left[\mathrm{Ca}^{2+}\right]$ ratio of 5 at ambient conditions ${ }^{40}$ (Fig. $3 \mathrm{a}$ and Supplementary Fig. 6). In these in vitro experiments, nanocrystal aggregates precipitated on the epicuticle of Ac. echinatior (Fig. 3b, c), and were identified as anhydrous high-magnesium calcite by XRD and EDS analyses (Fig. 3d and Supplementary Fig. 7). As a negative control, we performed the same in vitro mineralization experiments using the cuticle of the leaf-cutter ant Atta cephalotes, which belongs to the sister genus of Acromyrmex, does not have a biomineral cuticular layer, and has different cuticular structures (Supplementary Fig. 8). We found that only aragonite crystals formed, mainly on the hairs of At. cephalotes and almost never on the epicuticle (Supplementary Figures 9 and 10), indicating direct precipitation from solution since aragonite is the favorable crystalline precipitate in high-Mg conditions ${ }^{41}$. In control experiments using Ac. echinatior epicuticles either treated with $\mathrm{KOH}$ to hydrolyze surface proteins or coated with a $10 \mathrm{~nm}$ platinum layer to disable protein function, only aragonite crystals formed (Fig. 3d and Supplementary Fig. 7). Interestingly, in synthetic biomineralization experiments using cuticle from different developmental stages (pupae to fully mature adult workers), we found that only mature worker epicuticles catalyze the precipitation of high-magnesium calcite (Fig. 3e), consistent with the presence of a more substantial protein layer in mature workers indicated by SEM examination (Supplementary Figs. 11 and 12). These in vitro synthesis results, in particular the synthetic crystal morphology, are consistent with a solution containing organic molecules that may have originated in the ant thorax exoskeletons, suggesting that the protein layer in the epicuticle of Ac. echinatior and the unusual morphological structures on the cuticles of the ants catalyze the low-temperature nucleation and growth of magnesium-rich calcite on the epicuticles of mature workers of Ac. echinatior.

In vivo crystallization and growth of high-Mg calcite. To explore the developmental timing of biomineral formation on the epicuticles of Acromyrmex echinatior workers, we conducted rearing experiments. Twenty pupae at the same developmental stage were collected, randomly sorted into two groups of ten, and reared to callow adults (i.e., adults that have just emerged from the pupal stage), then one worker from each of the two groups was collected every second day and analyzed by XRD and eSEM (Fig. 3f, g). No biomineral layer was visible nor detected with XRD on workers 0 to 6 days after eclosion (emergence of the adult stage from the pupal stage). In contrast, 8 days after eclosion visible and XRD-detectable high-magnesium calcite was present on workers. Magnesium was rapidly integrated into the calcareous biomineral in these older workers, with XRD measurements of $\mathrm{mol} \% \mathrm{MgCO}_{3}$ reaching $\sim 35 \%$ within 2 days after the initiation of biomineralization on individual worker ants (i.e., from days 6 to 8 after eclosion; Fig. $3 \mathrm{~g}$ ).

Mechanical protection of epicuticular high-Mg calcite. It is plausible that epicuticular high-magnesium calcite enhances the structural robustness of the ant exoskeleton, providing better defense for ants engaged in 'wars' with other ants or under attack from predators or parasites. To test this hypothesis, we first 
a

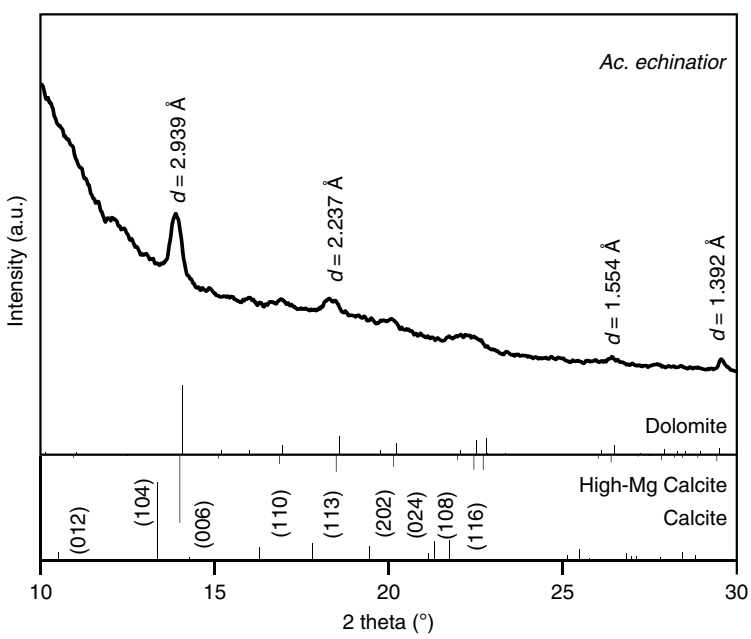

C

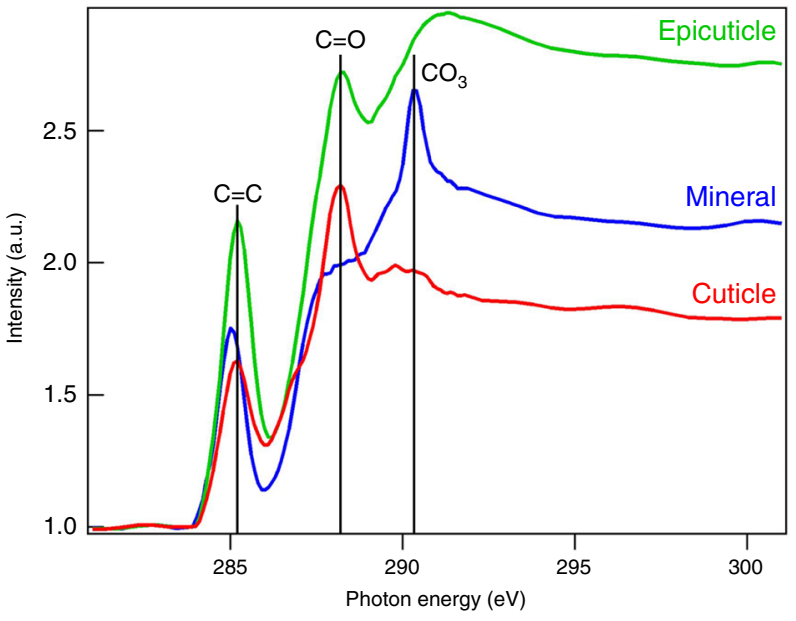

e

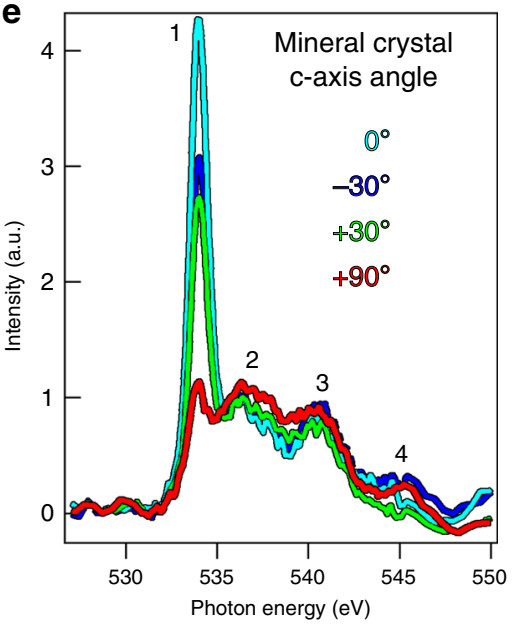

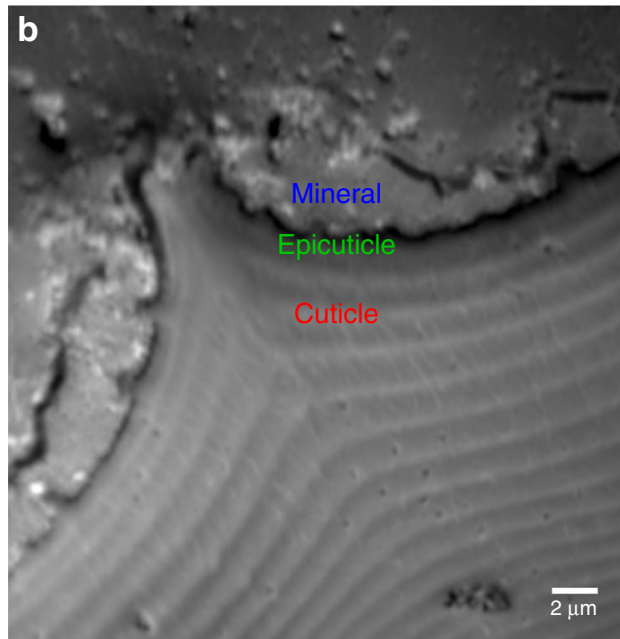
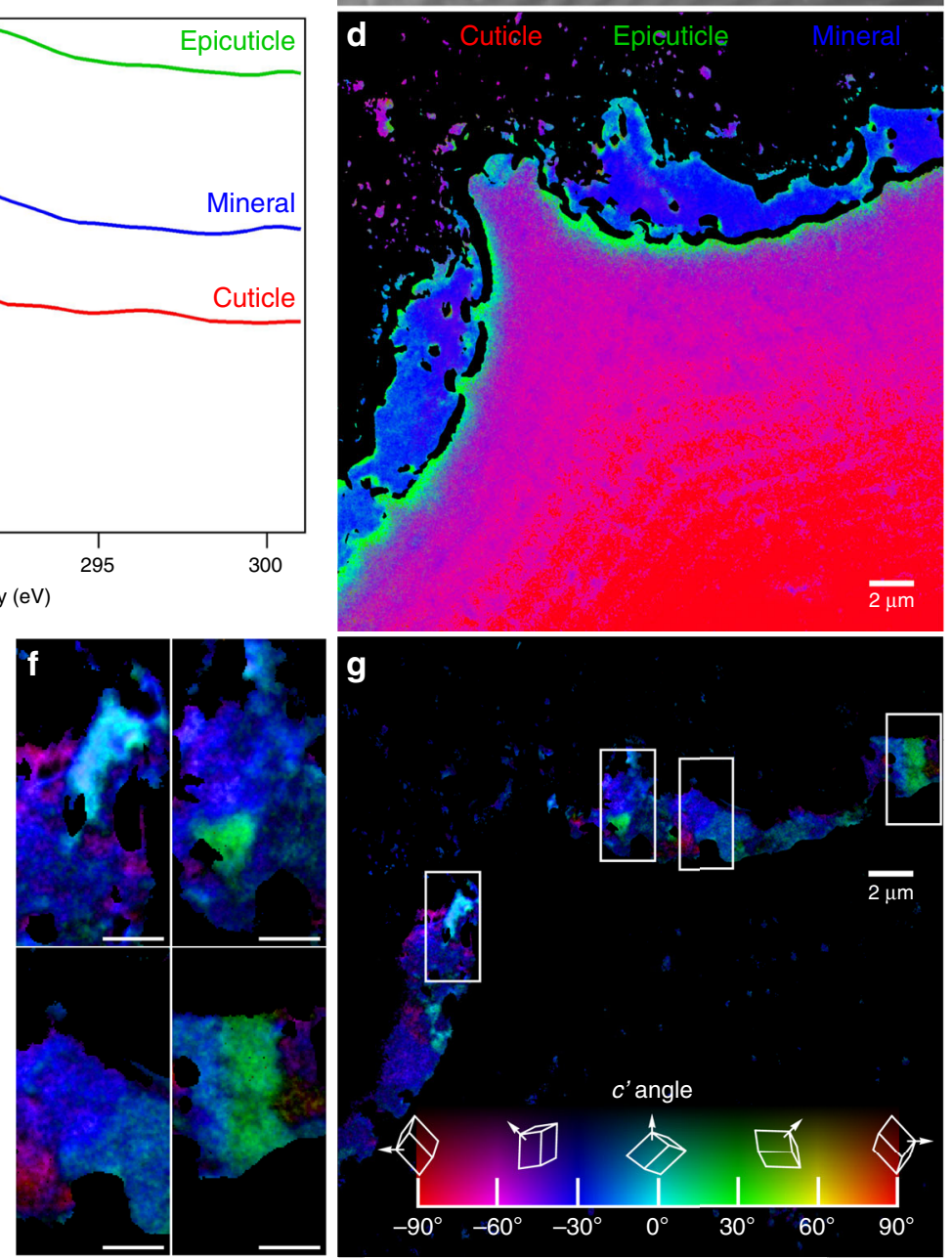

quantified the increase in hardness conferred by the protective biomineral layer using in situ nanoindentation in an SEM (Fig. 4a, Supplementary Fig. 13 and Supplementary Movie 1). Since the surface of the exoskeleton is not flat, conventional nanoindentation could not be used, whereas in situ nanoindentation with real-time microscopic imaging allowed nearperpendicular contact of the probe tip with the surface (Supplementary Fig. 13). Typical non-biomineralized ant cuticle, made primarily of chitin, has a hardness of $\mathrm{H} \sim 0.73 \pm 0.04 \mathrm{GPa}$ (Fig. $4 \mathrm{a}$ and Supplementary Fig. 14). In contrast, when high-magnesium calcite and cuticular layers are combined, the composite structure has a greater than two-fold increase in hardness $(1.55 \pm 0.48 \mathrm{GPa}$, compared to cuticle alone of $0.73 \pm 0.04 \mathrm{GPa}$ ) (Fig. 4a and Supplementary Figs. 14 and 15). Given that the biomineral layer has an average thickness of $2.3 \mu \mathrm{m}$ and that it overlays a cuticle with an average thickness of $33.5 \mu \mathrm{m}$, this more than two-fold increase in hardness is conferred by only a $7 \%$ increase in cuticle thickness (Supplementary Fig. 16). These cuticle thickness values agree with those reported by Peeters et al. ${ }^{42}$. Additional in situ nanomechanical testing of the cuticles of Atta cephalotes ants, which do not have a biomineral layer, as well as of other common insects, including a beetle (Xylotrechus colonus) and a honeybee 
Fig. 2 Chemical characterization of minerals on the cuticle of $\mathbf{A c}$. echinatior. a In situ XRD analysis identifying the cuticular crystalline layer as high-Mg calcite. $\mathbf{b}-\mathbf{g}$ XANES spectroscopy and mapping with PEEM of a cuticular cross-section. $\mathbf{b}$ Average of PEEM images acquired across the $\mathrm{C}$ K-edge, showing crystalline layer tightly attached to the cuticle. Three distinct component spectra were identified in the regions labeled cuticle, epicuticle, and mineral, from the most internal part of the ant to the outer surface. c Normalized component spectra extracted from the corresponding labeled regions. Characteristic peaks are marked, including the $285.2 \mathrm{eV}(\mathrm{C}=\mathrm{C}), 288.2 \mathrm{eV}(\mathrm{C}=\mathrm{O})$ and $290.3 \mathrm{eV}$ (carbonate) peaks. $\mathbf{d}$ Component map where each pixel is colored according to the chemical components it contains. Black pixels are masked areas containing epoxy or gaps. Faint carbonate components within the cuticle and epicuticle were emphasized by enhancing the blue channel $5 \times$, thus this is a semi-quantitative map. A fully quantitative RGB component map is presented in Supplementary Fig. 21. Individual maps of each component are presented in Supplementary Fig. 22, clearly showing an increasing gradient of carbonates towards the surface in the cuticle. e O K-edge spectra extracted from the mineral crystals correspondingly colored in the Polarizationdependent Imaging Contrast (PIC) maps in $\mathbf{f}$ and $\mathbf{g}$. $\mathbf{f}$ Magnified PIC maps for the regions represented by boxes in the complete PIC map in $\mathbf{g}$. $\mathbf{g}$ PIC map quantitatively displaying the orientations of the mineral crystals' c-axes in colors. This map was acquired from the same area shown in $\mathbf{b}$ and $\mathbf{d}$ at precisely the same magnification. These are interspersed high- and low-Mg calcite, and heterogenous at the nanoscale. Biomineral crystals do not show preferred orientations but are randomly oriented. High-magnesium calcite in carbon spectra is identified by the carbonate peak at $290.3 \mathrm{eV}$, which occurs in all carbonates, amorphous, or crystalline. The $\mathrm{O}$ spectra in $\mathbf{d}$ clearly indicate crystallinity, and their line shape indicates a mixture of high-magnesium calcite and low Mg-bearing calcite.

(Apis mellifera), produced similar hardness values in the range of 0.4-0.7 GPa (Fig. 4a and Supplementary Fig. 14) as they are all mainly made of chitin. The nano-mechanical measurements indicate that the biomineralized layer substantially hardens the exoskeleton of Ac. echinatior, consistent with the hypothesis that the biomineral layer functions as protective armor.

To further test the role of the biomineral as protective armor, we exposed Acromyrmex echinatior major workers with and without biomineral armor to Atta cephalotes soldiers in ant aggression experiments designed to mimic territorial 'ant wars' that are a relatively common occurrence in nature $31,43,44$. In direct combat with the substantially larger and stronger At. cephalotes soldier workers (average body length of $10.4 \mathrm{~mm}$ and a head capsule width of $6.1 \mathrm{~mm}$, compared to major Ac. echinatior body length of $6.4 \mathrm{~mm}$ and head capsule width of $2.9 \mathrm{~mm}$ ) (Fig. 4b), ants with biomineralized cuticles lost significantly fewer body parts (Fig. 4c and Supplementary Fig. 17) and had significantly higher survival rates compared to biomineral-free ants (Fig. 4d, Supplementary Movies 2 and 3). Further, in direct aggression experiments in which biomineral-armored Ac. echinatior workers were pitted against At. cephalotes soldiers, all of the At. cephalotes soldiers died, whereas only a few such deaths occurred when Atta soldiers were pitted against biomineral-free ants. SEM examination of biomineral-armored Ac. echinatior ants after combat with Atta cephalotes soldiers showed significantly less damage to their exoskeletons (Supplementary Fig. 18). Notably, biomineral armor is present in mature major workers, which forage outside of the nest, further indicating that epicuticular high-magnesium calcite is critical in a highly competitive environment (Supplementary Figs. 19 and 20). These results, taken together, are consistent with a role for epicuticular high-magnesium calcite as armor that defends workers from aggressive interactions with other ants, even though more ant species need to be further investigated.

Biomineral armor could also help protect ants from pathogens. In a series of experiments, we focused on entomopathogenic fungi, which establish infection by penetrating the insect exoskeleton and have significant impacts on survival. We exposed the propleural plates of Ac. echinatior major worker ants with and without biomineralized exoskeletons to the spores of the entomopathogenic fungus Metarhizium anisopliae (Ascomycota, Hypocreales). Compared to biomineral-free workers, major workers with biomineralized exoskeletons were significantly more resistant to infection. Specifically, we found that a majority of ants without biominerals died from infection within 4 days $(1.0 \pm 0.4$ and $0 \pm 0$ ants survived to 4 and 6 days, respectively), whereas an average of $2.2 \pm 0.4$ and $1.4 \pm 0.5$ (out of 3 individuals per subcolony over 5 sub-colonies) ants with biominerals survived to 4 and 6 days, respectively (Fig. $4 \mathrm{e})(P=0.05$; two-sample $t$-test). On day 6 , all ants had succumbed to infection, and examination of workers without biominerals exposed to M. anisopliae revealed substantial fungal growth and emergence (Fig. 4e, inset). In this experiment, a reduced abundance of the antibiotic-producing bacterial symbiont Pseudonocardia associated with the biomineral-free workers could have contributed to the reduction in survival.

\section{Discussion}

Three independent lines of evidence indicate that epicuticular biomineral crystals are ant-generated rather than adventitiously precipitated from the environment or generated by bacteria. First, in both $\mathrm{C}$ component maps (e.g., Fig. 2d) and PIC maps (e.g., Fig. 2f) the magnesium-rich calcite crystals outside the epicuticle are space-filling, a characteristic of biominerals formed by eukaryotes ${ }^{45}$. Second, magnesium-rich calcite biominerals are spatially co-localized with epicuticle protein(s), which are likely involved in biomineral formation, consistent with the absence of biomineral formation in in vitro synthesis experiments in which ant epicuticles were either coated with platinum or hydrolyzed. Third, the ant-rearing experiments were carried out in sterile, clean Petri dishes, eliminating the possibility of biominerals acquired from external sources.

The biota of the Ediacaran period (635-541 million years ago) included organisms of known and unknown phylogenetic affinities that lived in oceans with a high ratio of magnesium to calcium. Most were soft-bodied, but some possessed rudimentary skeletons composed either of aragonite (a form of calcium carbonate) or, notably, of high-magnesium calcite ${ }^{46}$. Around 550 million years ago, coinciding with a shift in the Earth's oceans to significantly lower magnesium-to-calcium ratios, metazoans with strongly calcified internal and external skeletons appeared, including the most familiar modern phyla. In spite of its strengthening properties, the enrichment of calcareous structures with high concentrations of magnesium in Cambrian and modern metazoans has until now remained only known from a very small plate within the tooth of sea urchins. The ability of fungusgrowing ants to facilitate the formation of magnesium-rich biominerals on their epicuticles is thus surprising. Further, given that fungus-growing ants are among the most extensively studied tropical insects, our finding raises the intriguing possibility that high-magnesium calcite biomineralization may be more widespread in insects than previously suspected, suggesting a promising avenue for future research.

Fungus farming in ants originated $\sim 60$ million years ago in South America when a hunter-gatherer ancestor irreversibly committed to subsistence-scale cultivation of fungal crops for 
a

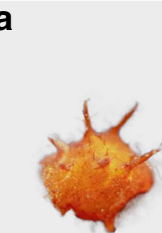

Ac. echinatior ant original cuticle

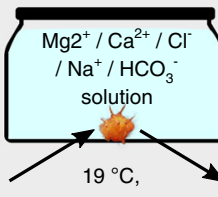

7 days

d
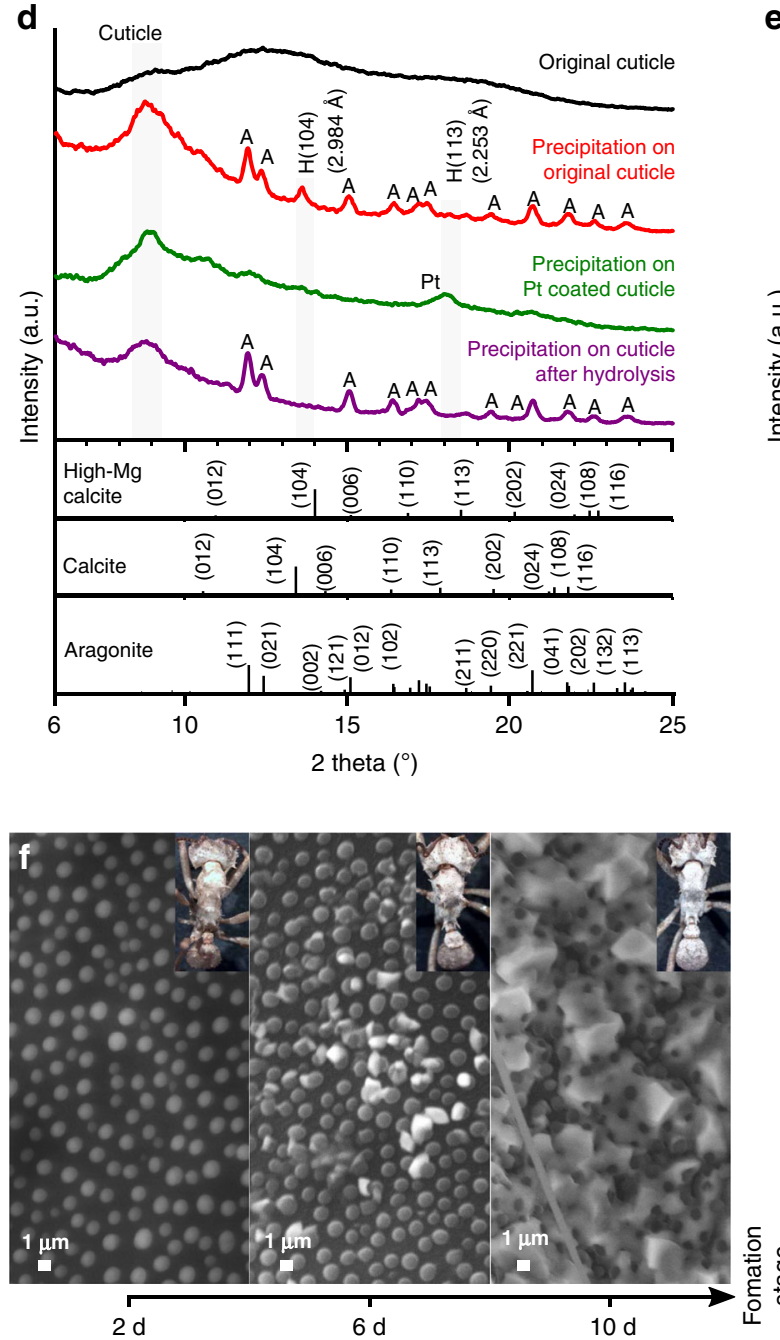
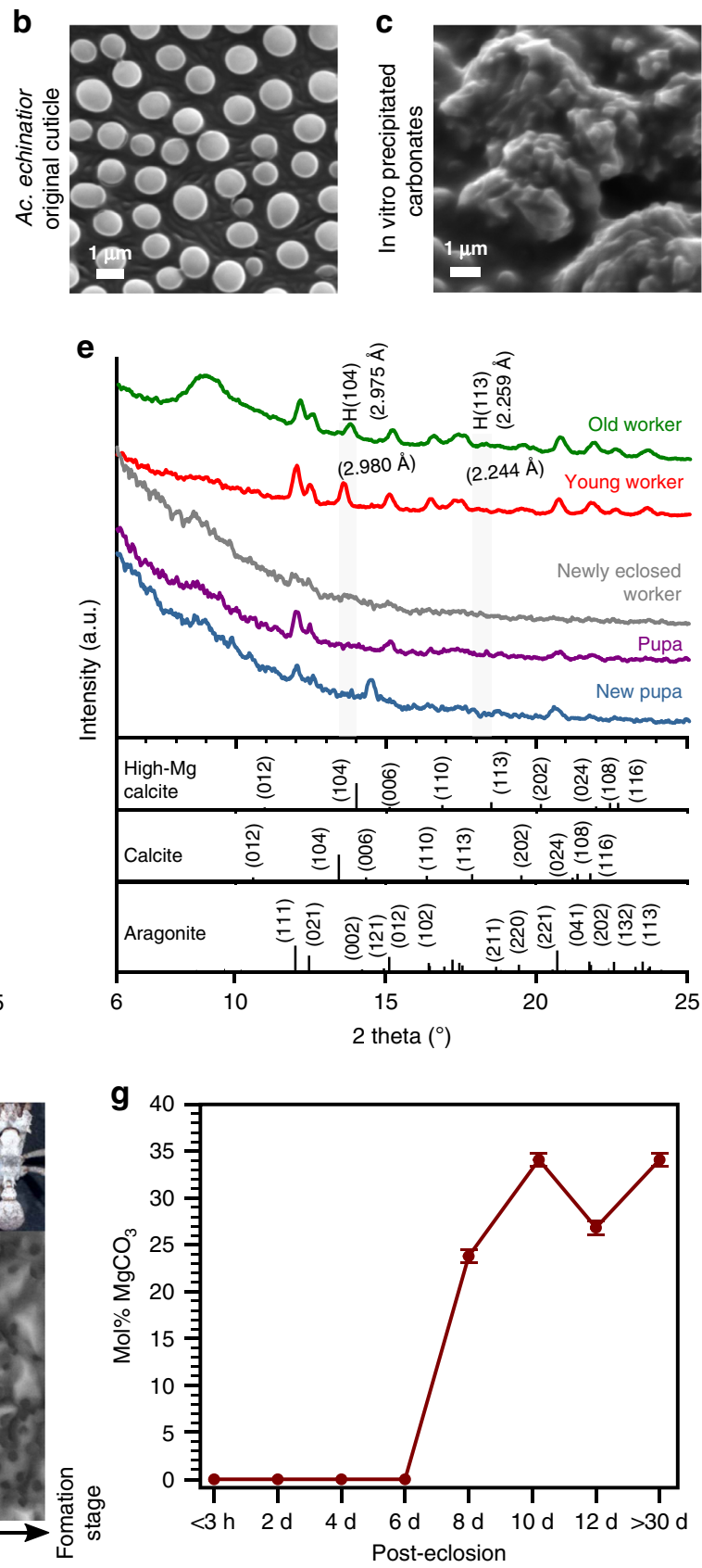

Fig. 3 Mineral precipitation on the cuticle in both in vitro cuticle synthetic studies and ant-rearing experiments. a Scheme of in vitro mineralization experiment using Acromyrmex echinatior leaf-cutting ant cuticles as templates for biomineralization (Photo C.M.C.). b, c Pre- and post-incubation SEM images showing the original, uncoated cuticle $(\mathbf{b})$ and the cuticle covered by a layer of precipitated carbonate $(\mathbf{c})$ after incubation in $\mathrm{Mg}^{2+} / \mathrm{Ca}^{2+} / \mathrm{Cl}^{-} /$ $\mathrm{Na}^{+} / \mathrm{HCO}_{3}{ }^{-}$solution for 7 days at $19{ }^{\circ} \mathrm{C}$. d, XRD patterns of, from top to bottom, an uncoated ant cuticle, a cuticle after incubation in $\mathrm{Mg}^{2+} / \mathrm{Ca}^{2+} / \mathrm{Cl}^{-} /$ $\mathrm{Na}^{+} / \mathrm{HCO}_{3}{ }^{-}$solution, a platinum-coated cuticle incubated in $\mathrm{Mg}^{2+} / \mathrm{Ca}^{2+} / \mathrm{Cl}^{-} / \mathrm{Na}^{+} / \mathrm{HCO}_{3}{ }^{-}$solution, and a cuticle after $\mathrm{KOH}$ protein hydrolysis incubated in $\mathrm{Mg}^{2+} / \mathrm{Ca}^{2+} / \mathrm{Cl}-/ \mathrm{Na}^{+} / \mathrm{HCO}_{3}{ }^{-}$solution. $\mathrm{H}$ : high-magnesium-calcite, $\mathrm{A}$ : aragonite, Pt: platinum. e XRD patterns of cuticles of ants representing different developmental stages, ranging from (from bottom to top), a newly formed pupa to an older worker, after incubation in $\mathrm{Mg}^{2+} / \mathrm{Ca}^{2+} / \mathrm{Cl}^{-} / \mathrm{Na}^{+} / \mathrm{HCO}_{3}{ }^{-}$ solution. $\mathbf{f}$ Environmental scanning electron micrographs (eSEM) of ant epicuticles taken over a 10-day time series, from immediately after eclosion from pupa to adult (left), to 10 days post-eclosion (right), showing the formation of the biomineral layer over time (Photo H.L.). $\mathbf{g}$ Estimated magnesium concentration of the biomineral layer during 30 days of ant development based on the XRD $d_{(104)}$ value according to Graf and Goldsmith 64 , showing the rapid integration of magnesium from days 6 to 8 and the continued presence of high-magnesium content for up to 30 days ( $n=2$ per treatment and the corresponding standard error are shown).

food ${ }^{47}$. The transition to industrial-scale agriculture occurred $\sim 20$ million years ago with the origin of the ecologically dominant leaf-cutting ants, in which colony populations are orders of magnitude greater in size and in which physically distinct worker castes enable the complex division of labor, paralleling the similar importance of agriculture in driving the expansion of human populations and the elaboration of human social systems ${ }^{48}$. Further paralleling human agriculture, the fungal cultivars of the ants are highly susceptible to pathogens and the ants have responded, in part, by evolving associations with antibiotic- 


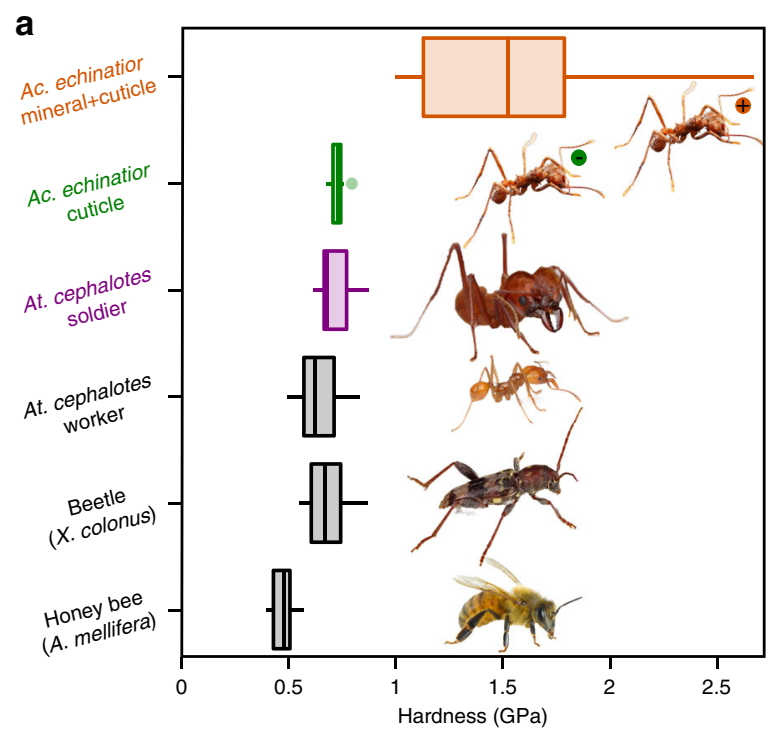

b
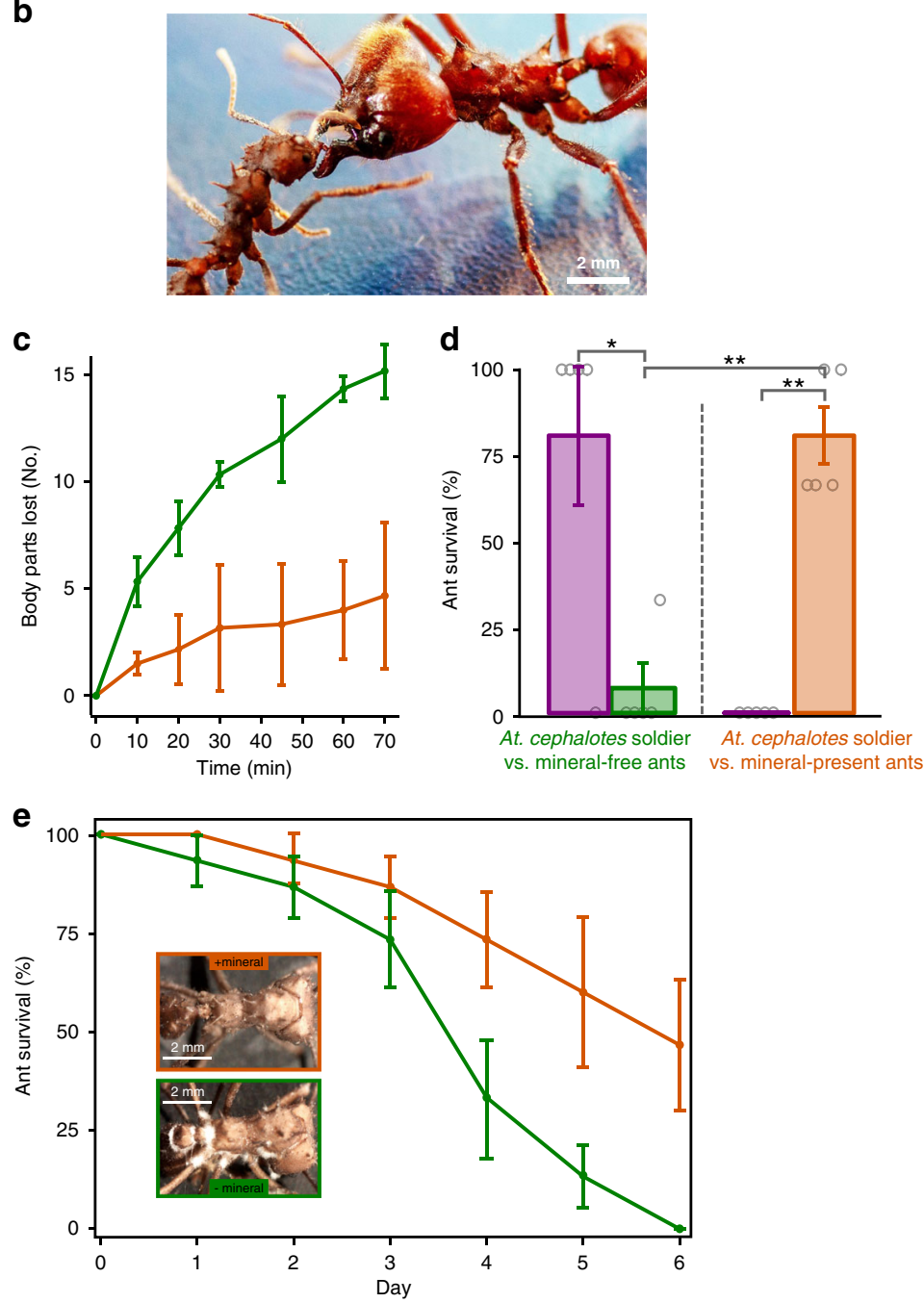

producing bacteria to protect their crops $^{28}$. Early sedentary human agricultural settlements represented rich resources that were highly susceptible to marauding bands of human raiders, leading to the development of multiple modes of defense, including specialized warrior castes, fortified cities, weapons, and protective armor ${ }^{40}$. Here we show that, in another striking parallel with agriculture-driven human cultural evolution, fungus-growing ants have evolved biomineralized armor that serves, at least in part, both to protect them from other ants, including other fungus-growing ants, in disputes over territory and agro-predatory ants that are known to raid their colonies and to consume their gardens and brood, and protect them from 
Fig. 4 Mechanical protection afforded by the epicuticular mineral layer. a Quantitative nano-mechanical properties of insect cuticles, including honeybee (Apis mellifera), beetle (Xylotrechus colonus), leaf-cutting ants [Atta cephalotes worker, Atta cephalotes soldier (purple), and Acromyrmex echinatior worker without biomineral (green, with green minus circle beside the ant image)] and Ac. echinatior ant worker with biomineral epicuticular layer (orange, with orange plus circle beside the ant image), measured by an in situ nanoindenters with a cube-corner probe $(n=12,15,13,15,12$, and 13 for insect measured above, respectively; center, median; box, upper and lower quantiles; whisker, $1.5 \times$ interquartile range; points, outlier). Atta ants images, Xylotrechus beetle image, and Apis bee image provided with permission from the copyright holder, Alexander L. Wild, Jon Rapp, and Don Farrall, respectively. b-d Aggressive interaction between three Ac. echinatior workers (with/without biomineral, respectively) and Atta cephalotes soldier (Photo C.M.C.). b Ac. echinatior worker (left) aggressively interacts with Atta cephalotes soldier (right). c In aggressive encounters with Atta cephalotes soldiers, Ac. echinatior workers with biomineral armor (orange) lose substantially fewer body parts (i.e., legs, antennae, abdomen, and head) compared to Ac. echinatior worker without biomineral (green). d Survivorship of Ac. echinatior workers without (green) and with (orange) biomineral armor in aggressive encounters with Atta cephalotes soldiers (purple). Asterisks indicate significant differences via a two-sample $t$-test $\left({ }^{\star} P<0.05,{ }^{\star} p<0.001 ; P\right.$-value $=0.0184,0.0001$, and 0.0006 from left to right, respectively; $n=5$ per treatment and the corresponding standard error are shown.). e Survivorship curves of Ac. echinatior worker with (orange) and without (green) an epicuticular biomineral layer exposed to the entomopathogenic fungus Metarhizium. The inset images show more substantial fungal growth and emergence from biomineral-free workers (Photo H.L.). c, e $n=3$ per treatment, and the corresponding standard error are shown.

disease organisms that might otherwise spread rapidly in their densely populated colonies.

\section{Methods}

Ants. The fungus-farming ants used in this study were Acromyrmex echinatior and Atta cephalotes, originally collected in Costa Rica and Panama, and subsequently maintained in the lab. These ant species co-occur in the same nesting areas in Panama and other regions.

PhotoEmission electron microscopy (PEEM). Acromyrmex echinatior ants were freeze-dried prior to PEEM sample preparation. The heads of the ants were then detached and embedded in Epofix epoxy (EMS, Hatfield, PA), ground with SiC sandpapers, polished with $\mathrm{Al}_{2} \mathrm{O}_{3}$ suspensions of $300 \mathrm{~nm}$ (MicroPolish II, Buehler, Lake Bluff, IL) and $50 \mathrm{~nm}$ (Masterprep, Buehler, Lake Bluff, IL) particle sizes ${ }^{8,49}$. $22 \mathrm{~g} / \mathrm{L} \mathrm{Na}_{2} \mathrm{CO}_{3}$ saturated solution was added regularly onto the pad during grinding and polishing to prevent carbonate dissolution, and the $\mathrm{Al}_{2} \mathrm{O}_{3}$ suspensions were also dialyzed against $22 \mathrm{~g} / \mathrm{L} \mathrm{Na}_{2} \mathrm{CO}_{3}$ saturated solution ${ }^{50}$. The samples were re-embedded to fill as much as possible the interior of the ants and the gap between mineral and epoxy, and then the polishing procedures were repeated. After final polishing, the samples were rinsed with ethanol and gently wiped with TexWipe Cotton (Texwipe, Kernersville, NC), air-dried, and coated with $1 \mathrm{~nm} \mathrm{Pt}$ on the areas to be analyzed and $40 \mathrm{~nm} \mathrm{Pt}$ around it ${ }^{51}$

For C K-edge spectra, PEEM stacks were acquired by scanning across 280-320 $\mathrm{eV}$ range with $0.1-\mathrm{eV}$ step between 284 and $292 \mathrm{eV}$, and $0.5-\mathrm{eV}$ step elsewhere, resulting in 145 images per stack ${ }^{35}$. For O K-edge spectra, PEEM stacks were acquired by scanning across $525-555 \mathrm{eV}$ range with $0.1-\mathrm{eV}$ step between 530 and $545 \mathrm{eV}$, and $0.5-\mathrm{eV}$ step elsewhere, resulting in 181 images per stack ${ }^{52,53}$. The images were stacked and processed with GG Macros in Igor Pro 6.3754.

For PIC mapping, a stack of 19 images was acquired by fixing the photon energy at the $\mathrm{O}$ K-edge $\pi^{*}$ peak $(534 \mathrm{eV})$ and changing the X-ray polarization from horizontal to vertical with a $5^{\circ}$ step $^{49,52,55}$. Colored PIC maps were then produced using Igor Pro 6.37 with GG Macros ${ }^{54}$.

Masking the component map. The component map in Fig. $2 \mathrm{~d}$ was masked using an image of the same region acquired in SEM in backscattered electron (BSE) mode. Unfortunately, in both the PEEM average image in Fig. $2 \mathrm{~b}$ and in the BSE image, the gray levels in the embedding epoxy and those in the cuticle are similar. Therefore, there is no rigorous and quantitative method to select one but not the other. We used Adobe Photoshop and the Magic Wand tool with a tolerance of 30 to select all of the cuticles and deleted all those pixels from a black mask. The brighter mineral and all of the mineral debris deposited on the epoxy were then selected using the Magic Wand and a tolerance of 50 on the BSE image. These were also deleted from the same black mask. The black pixels in the BSE image correspond to gaps between the cuticle and the epoxy, or holes between mineral crystals, those black pixels were remained black in the black mask. The bright mineral debris is presumably an artifact of polishing, as they appear both in PEEM and SEM images and are spectroscopically identified without a doubt as a mineral. These were also removed from the mask and therefore displayed in Fig. 2d, as removing them would have been an artifact. The BSE image was warped to correspond correctly to the PEEM image using Adobe Photoshop and specifically the Puppet Warp tool.

Obtaining component spectra. We extracted single-pixel spectra from the cuticle, the epicuticle, and the mineral regions. These were identified as the only three reliable components that were spectroscopically distinct from one another and not linear combinations of other components. The single-pixel spectra from the same material were extracted from each stack, aligned in energy, and averaged. The averaged spectrum was then normalized to the beamline $I_{0}$ curve, acquired with precisely the same energy steps.

The three spectra were then aligned between 280.0 and $283.7 \mathrm{eV}$. The cuticle and epicuticle spectra were shifted in energy so that the first peak was at $285.2 \mathrm{eV}$ for chitin and proteins, following Cody et al. ${ }^{38}$, whereas the mineral spectra were shifted in energy so that the last peak, characteristic of carbonates, was at $290.3 \mathrm{eV}$, following Madix and Stöhr ${ }^{56,57}$. The cuticle spectrum is identical to that published by Cody et al. 2011 obtained from scorpion cuticle and interpreted as chitin. The spectrum has a peak at 285.2 corresponding to $\mathrm{C}=\mathrm{C}$ in aromatic carbon, a shoulder at $\sim 287 \mathrm{eV}$, and a peak at $288.2 \mathrm{eV}$ corresponding to $\mathrm{C}=\mathrm{O}$ in chitin. The epicuticle spectrum shows the characteristics $\mathrm{C}=\mathrm{C}$ of aromatic amino acids (tyrosine, tryptophan, and phenylalanine $)^{39}$, a shoulder at $287.6 \mathrm{eV}$ corresponding to $\mathrm{C}-\mathrm{H}$ aliphatic carbon, and a sharp peak at $288.2 \mathrm{eV}$ corresponding to the carboxyl group $(\mathrm{C}=\mathrm{O})$ in the peptide bonds of all proteins. Compared to the spectra in tyrosine and tryptophan, the phenylalanine spectrum has a more symmetric peak at $285.2 \mathrm{eV}$, allowing us to assign this peak to phenylalanine in the epicuticle ${ }^{38}$. The $\mathrm{C}=\mathrm{O}$ occurs at the expected 288.2 $\mathrm{eV}^{35}$. These normalized and averaged spectra were then adopted as component spectra, displayed in Fig. 2c, and used to obtain a component map in Fig. 2d.

Component mapping. The extracted, averaged, normalized, and aligned component spectra were made references by multiplying the $I_{0}$. Spectrum in each pixel of the stack was analyzed and best-fitted to a linear combination of the component references: cuticle, epicuticle, and mineral. The resulting component proportion maps were exported as a gray level image and combined by the Merge Channel function in Adobe Photoshop, which became a fully quantitative RGB image (Supplementary Fig. 21). Individual component distribution maps were presented in Supplementary Fig. 22. For Fig. 2d, we enhanced the blue channel by adjusting the midtone value in levels five times greater than the other two channels, to emphasize the presence of a mineral in the cuticle and epicuticle.

In vitro synthesis. All synthesis experiments were carried out in sealed plastic bottles at $19^{\circ} \mathrm{C}$ for $7 \mathrm{~d}$. Solutions were prepared by dissolving $50 \mathrm{mM} \mathrm{MgCl} \cdot 6 \mathrm{H}_{2} \mathrm{O}$, $10 \mathrm{mM} \mathrm{CaCl}_{2} \cdot 2 \mathrm{H}_{2} \mathrm{O}$, and $50 \mathrm{mM} \mathrm{NaHCO}$ with $\mathrm{pH}$ buffer to $\sim 8.0$ with $\mathrm{NaOH}$ to simulate modern seawater chemistry. The solution was mixed for $20 \mathrm{~min}$ and then divided into $100 \mathrm{~mL}$ bottles with ant exoskeleton (Supplementary Fig. 6). Peptide synthesis experiments with $1 \mathrm{mM}, 5 \mathrm{mM}$, and $10 \mathrm{mM}$ of phenylalanine peptide $(\mathrm{H}-$ Phe-Phe-Phe-OH) (Bachem, CA) were mixed into solutions without ants. All vessels during the experiments have been washed with deionized water and pretreated with $6 \mathrm{M}$ hydrochloric acid to prevent carbonate contamination. Filters and ants were air-dried for XRD and SEM characterization.

\section{Scanning electron microscopy (SEM) and electron backscatter diffraction} (EBSD). Scanning electron microscopy (SEM) was done using a Hitachi S3400 at $15 \mathrm{kV}$. Images were obtained in both variable pressure and vacuum mode. Energydispersive X-ray spectroscopy (EDS) and electron backscatter diffraction (EBSD) was carried out using an AZtecOne system with silicon-drift detector from Oxford instruments. Samples were coated with $5 \mathrm{~nm}$ Pt coating. Phases used in EBSD are constructed based on Mg-poor ( $a=4.990 \AA, c=17.062 \AA$ ), Mg-medium ( $a=$ $4.920 \AA, c=16.656 \AA$; calculated), Mg-rich $(a=4.850 \AA, c=16.250 \AA)$ regions. However, given the EBSD is not particularly sensitive to unit-cell parameter differences, chemical heterogeneity from EBSD is only qualitative.

Transmission electron microscopy (TEM). TEM measurements were carried out using a Philips CM200UT TEM instrument operating at $200 \mathrm{kV}$ acceleration voltage with $0.5 \mathrm{~mm}$ spherical aberration (Cs) and a point resolution of $0.19 \mathrm{~nm}$. Images and electron diffraction were collected with a CCD camera and analyzed with Gatan DigitalMicrograph software. Samples that have been previously 
examined by XRD and SEM were rinsed with ethanol and DI water to remove glue residue. Samples were then crushed in an agar mortar, suspend in acetone, and drop onto Lacey/ carbon 200 mesh copper grid. The composition of phases was confirmed with energy-dispersive X-ray spectroscopy (EDS) and analyzed with Thermo Noran software.

In situ X-ray diffraction (XRD) analyzes. In situ X-ray diffraction (XRD) was performed using a Rigaku Rapid II X-ray diffraction system with Mo Ka radiation. This XRD instrument uses a 2-D image-plate detector for signal collection and integrated using Rigaku's 2DP software. XRD was run at $50 \mathrm{kV}$ and a $100-\mu \mathrm{m}$ diameter collimator. Whole fresh ant samples were glued onto an American Durafilm Kapton $^{\circledast}$ tube with vacuum grease. Ant samples were then spin around phi and oscillate on omega. Synthesized powder samples were sealed in Kapton tube and run with fixed omega and phi spin. Refinements for phase percentage and unit-cell parameters were run using Jade 9.0 software with American Mineralogist Crystal Structure Database (AMCSD) and the PDF-4+ database from the International Centre for Diffraction Data (ICDD). Disordered dolomite reference was constructed based on the unit-cell parameter of disordered dolomite with $50 \mathrm{~mol} . \%$ $\mathrm{MgCO} 3$ and powder diffraction pattern calculated by CrystalMaker built-in CrystalDiffract software.

Sectioning and transmission electron microscopy (TEM). Ants for sectioning and transmission electron microscopy were fixed in cold $2 \%$ glutaraldehyde in Nacacodylate buffer. Postfixation was done in $2 \%$ osmium tetroxide and specimens were subsequently dehydrated in a graded acetone series. Specimens were embedded in Araldite and sectioned with a Reichert Ultracut E microtome. Semithin 1- $\mu \mathrm{m}$ sections for light microscopy were stained with methylene blue and thionin. Double-stained 70-nm thin sections were examined in a Zeiss EM900 electron microscope.

Quantitative electron probe micro-analysis (EPMA). The carbonate EPMA data were acquired with a CAMECA SXFive FE electron probe in the Cameca Electron Probe Lab in the Department of Geoscience at the University of Wisconsin-Madison. Operating conditions were $7 \mathrm{kv}$ and $10 \mathrm{nA}$ (Faraday cup), using a focused beam. A low accelerating voltage was used to shrink the analytical volume to less than $300 \mathrm{~nm}$. Peak counting time was $10 \mathrm{~s}$, with background acquired for $10 \mathrm{~s}$. Mg Ka was acquired with a TAP crystal and Ca Ka with an LPET crystal. The standard used as Delight Dolomite. Automation and data reduction utilized Probe for EPMA (Probe Software), Carbon and oxygen were accounted for in a robust procedure in the Probe for EPMA software: oxygen was calculated based upon stoichiometry to the measured $\mathrm{Mg}$ and $\mathrm{Ca}$, with carbon calculated relative to that oxygen value $(1: 3)$, with this being iterated several times within the Armstrong/Love Scott matrix correction. The resulting values were then evaluated for actual accuracy, based upon two criteria: a non-normalized analytical total close to $100 \mathrm{wt} \%(\sim 98-102 \mathrm{wt} \%)$, and for a formula basis of 3 oxygens, the carbon formula value being close to $1.00(\sim 0.99-1.01)$. With these conditions met, the determined compositions were deemed acceptable.

\section{Raman and attenuated total reflectance Fourier-transform infrared (ATR-}

FTIR) spectroscopy. Ant mineral samples for Raman experiments were prepared by bleaching the freeze-dried ant samples in $8.25 \% \mathrm{NaClO}$ commercial bleach for $24 \mathrm{~h}$ at room temperature to remove the exposed organic materials ${ }^{11}$. Raman spectra were collected using a LabRam Raman microprobe (JY Horiba, Inc.) equipped with a Microscope (Olympus DX41, $\times 50$ and $\times 100$ objectives) and a 633 $\mathrm{nm}$ laser. Spectra were acquired with a CCD camera behind a spectrometer (the accumulations and integration time varied). The ant carbonate powders were dropped on a microscope slide just before individual measurement.

For ATR-FTIR, freeze-dried ant samples were used directly. ATR-FTIR data collection was conducted on a Perkin-Elmer 1720x spectrometer according to the manufacturer's instructions.

Rearing experiments. In a total of 20 worker pupae of Ac. echinatior at the same developmental stage and its $\sim 10 \mathrm{~g}$ fungus garden were collected and randomly sorted into two groups of ten and maintain them in chambers (diameter $6 \mathrm{~cm}$, height $4 \mathrm{~cm}$ ) with wet cotton. Reared to callow workers (around $3 \mathrm{~h}$ ) and followed by one worker from each of two groups was collected every second day. The fresh ant samples were subjected to XRD analyses immediately and followed by an Environmental scanning electron microscope examination (eSEM). For eSEM, an FEI QUANTA 200 eSEM (FEI Company) was used. Ants were placed directly onto the eSEM stub and examined without any preparation (i.e., samples were not fixed or coated for this analysis). All samples were analyzed at 5.0 torr, 3.0 spot size, and $4{ }^{\circ} \mathrm{C}$.

Ant sample preparation for SEM analyses of the cuticular structure. Worker ant cuticles from Ac. echinatior at different developmental stages (pupae to fully mature adult workers) and At. cephalotes were immediately fixed with $4 \%$ (vol/vol) formaldehyde and $1 \%$ glutaraldehyde at $22^{\circ} \mathrm{C}$ RT overnight. Samples were then washed with PBS and treated with $1 \%$ osmium tetroxide for $30 \mathrm{~min}$ at $22^{\circ} \mathrm{C}$. Samples were subsequently washed with a series of increasing ethanol dilutions
(30-100\% [ $\mathrm{vol} / \mathrm{vol}])$, followed by critical point drying and coating with 1-nm platinum. Scanning electron microscopy (SEM) of samples was performed using a LEO 1530 microscope to investigate the cuticular structure.

High-performance liquid chromatography (HPLC) analysis. Dissected ant cuticle samples were placed in $100 \mu \mathrm{L} 25 \%$ TFA containing $10 \mathrm{mM}$ DTT and were hydrolyzed at $110^{\circ} \mathrm{C}$ for $24 \mathrm{~h}$. Hydrolyzed samples were then dried at $45^{\circ} \mathrm{C}$ under a stream of nitrogen and resuspended in $50 \mathrm{mM} \mathrm{HCl}$. Amino acids were then converted into respective fluorescent derivatives using $o$-phthalaldehyde (OPA) (Agilent \#5061-3335). Briefly, $5 \mu \mathrm{L}$ sample aliquot was added to $20 \mu \mathrm{L}$ of $40 \mathrm{mM}$ potassium tetraborate buffer ( $\mathrm{pH}$ 9.8) followed by the addition of $5 \mu \mathrm{L} \mathrm{OPA}$, mixed gently and another $40 \mu \mathrm{L}$ water was added. The mixture was filtered through a 0.45 $\mu \mathrm{m}$ cellulose acetate 4 -mm syringe filter (Nalgene \#171-0045). Freshly prepared samples were immediately subjected to HPLC analysis.

Amino acids were analyzed using a modified method $^{58}$. In brief, the apparatus used was a custom-built dual analytical/semi-preparative Shimadzu system consisting of a SIL-20AC autosampler, a CBM-20A system controller, two LC20AR pumps, a C50-20AC oven, a PDA S10-M20A detector, and a CPP-10Avp detector. Chromatographic separation of OPA-derivatized amino acids was performed using an Agilent ZORBAX Eclipse AAA column $(4.6 \mathrm{~mm} \times 150 \mathrm{~mm} \times$ $3.5 \mu \mathrm{m}$; Agilent \#963400-902) coupled with a ZORBAX Eclipse AAA Analytical Guard Column $(4.6 \mathrm{~mm} \times 12.5 \mathrm{~mm} \times 5 \mu \mathrm{m}$; Agilent $\# 820950-931)$ heated at $40{ }^{\circ} \mathrm{C}$. The gradient elution was applied using $40 \mathrm{mM}$ sodium phosphate dibasic buffer $(\mathrm{pH} 7.8)$ as solvent $\mathrm{A}$ and a mixture of acetonitrile, methanol, and water (45:45:10, $\mathrm{v} / \mathrm{v} / \mathrm{v})$ as solvent B. HPLC-grade acetonitrile and methanol were supplied from Fisher Scientific and were used without further purification. The optimum separation of amino acids was obtained using the following gradient program: $0 \% \mathrm{~B}$ for $1.9 \mathrm{~min}$, then increase to $57 \% \mathrm{~B}$ up to $28.10 \mathrm{~min}$ followed by an increase to $100 \% \mathrm{~B}$ up to $38.60 \mathrm{~min}$, then hold at $100 \% \mathrm{~B}$ till $47.30 \mathrm{~min}$, and decrease to $22.3 \%$ B up to $48.20 \mathrm{~min}$ and down to $0 \% \mathrm{~B}$ till $60 \mathrm{~min}$. The flow rate was $1 \mathrm{~mL} / \mathrm{min}$. Aliquots of $10 \mu \mathrm{L}$ standards/samples were injected at $0.5 \mathrm{~min}$ and amino acids were detected at the maximum wavelength of $338 \mathrm{~nm}$ with a $4 \mathrm{~nm}$ bandwidth. Retention times, as well as spectral information, was given by the PDA detector was used for peak identification. Calibration curves of individual and mixed amino acids were prepared using either $250 \mathrm{pmol}$ stocks of corresponding individual amino acids or a 250 pmol amino acid standard mix (Agilent \#5061-3331). Quantification was performed using the calibration curves of the respective amino acid standards.

Biomineral-free Ac. echinatior ant generation. Biomineral-free Ac. echinatior ants were generated using a sub-colony setup. Sub-colonies were set up in small (diameter $6 \mathrm{~cm}$, height $4 \mathrm{~cm}$ ) clear plastic containers. After sterilizing containers for at least $20 \mathrm{~min}$ using UV light, cotton moistened with distilled water was placed at the bottom to help provide humidity. A small (width $4.12 \mathrm{~cm}$, length $4.12 \mathrm{~cm}$, and height $0.79 \mathrm{~cm}$ ) weigh boat (Fisher catalog \#08-732-112) was placed on top of the wet cotton, and then $0.1 \mathrm{~g}$ of the fungus garden, 2 minor workers, and a major worker pupa being reared to derive a biomineral-free adult ( $n=10$ sub-colonies) A $\sim 1 \mathrm{~cm}^{2}$ leaf fragment of pin oak (Quercus palustris) was added $24 \mathrm{~h}$ or more after pupa eclosion for the ants to cut and incorporate into the fungus garden. We monitored sub-colonies daily to record the eclosion date for the major worker pupa until 14-21 days after eclosion. Then we performed environmental Scanning Electron Microscopy (eSEM) and XRD on a subset of the ants to confirm the absence of the biomineral. Meanwhile, we established that Ac. echinatior ants could grow a biomineral layer normally in sub-colonies with the addition of two major worker adults ( $n=10$ sub-colonies) and other colony components were maintained as above.

Nano-mechanical testing. Nanoindentation tests were carried out using a Bruker Hysitron PI-85 SEM Picoindenter in a Zeiss Leo 1550VP SEM at the Wisconsin Centers for Nanoscale Technology, UW-Madison. The samples were tested using a cube-corner probe with a basic quasistatic trapezoid load-controlled function, where the maximum load was $500 \mu \mathrm{N}$, the hold time was $2 \mathrm{~s}$, and the loading/ unloading rate was $100 \mu \mathrm{N} / \mathrm{s}^{59}$. SEM imaging was done in a high vacuum using an accelerating voltage of $3 \mathrm{kV}$ with secondary electron mode. In order to simulate the defense mechanism of the actual ant exoskeleton, we tested the combination of ant mineral and ant cuticle by indenting from the outside in, as illustrated in Supplementary Fig. 13. The samples for testing the combination of ant mineral and an cuticle were prepared by slicing through the transverse plane of the head of the ant to allow probing only on the flatter top part of the head. All samples were then attached firmly to carbon tape on an SEM stub. The combination sample was additionally pressed carefully with tweezers to ensure good attachment and flatness. The indentation data and corresponding SEM video were analyzed not only to ensure that the correct contact point of the probe with the surface was chosen, but also that there was no movement of the sample during indentation, as well as that the load-displacement curve was smooth and there was no abrupt pop-out or discontinuity. Based on these criteria, 13,13, 10, and 12 valid data points were selected for Ac. echinatior ant mineral plus cuticle and Ac. echinatior ant cuticle cross-section, respectively. Measurements on other insect cuticles were also done by indenting from the outside in following the same analyzing criteria, with which 15, 13, 15, and 12 valid data points were selected for Atta soldier ant cuticle, Atta 
worker ant cuticle, beetle elytra, and honeybee cuticle, respectively. All the valid points were then used to obtain the hardness values ${ }^{60}$ presented in Fig. $4 \mathrm{a}$. Additional hardness comparison of the mineral phases alone was done on polished cross-sections of geologic dolomite and Ac. echinatior mineral. Cross-section samples were prepared using the same embedding and polishing procedures as described for the PEEM samples. Representative load-depth curves in Supplementary Fig. 14 were selected from the data point closest to the averaged hardness value in each sample.

\section{Aggressive experiments between At. cephalotes soldier and Ac. echinatior} workers. We confronted one major At. cephalotes soldier and three mineral-present/mineral-free workers of Ac. echinatior ${ }^{61}$. The experiment was replicated 5 times under reduced light in $9 \mathrm{~cm}$ Petri dishes. The survival of ants was counted after $3 \mathrm{~h}$ of confrontation.

Using the time-lapse setting of an iPad Pro 2018, we recorded aggressive encounters between At. cephalotes soldier and Ac. echinatior workers (Supplementary Movies S2 and S3). For the aggressive experiments with mineralpresent ants, the video was started when At. cephalotes soldier was placed in the petri dish with the Ac. echinatior ants. The video was stopped when the soldier ant was killed and the Ac. echinatior worker was able to separate from the soldier ant. The video is a total of $42 \mathrm{~min}$ filmed in time-lapse at 120 times its speed reducing the video to $21 \mathrm{~s}$ in length, followed by editing it down to $10 \%$ of its speed using Premiere Pro resulting in a 3:27 min video. For the aggressive experiments with mineral-free ants, the video was started when the soldier ant was placed into the petri dish, video was stopped after all three Ac. echinatior ants were killed by the soldier ant. The video was recorded for $1 \mathrm{~h}$ in time-lapse at 120 times its speed reducing the video to $30 \mathrm{~s}$ in length, followed by editing down to $10 \%$ of its original speed resulting in a video that is 5:00 min. The counting of lost body parts was based on the video record.

Entomopathogenic fungi infection. Using two groups of Ac. echinatior major worker ants in which the mineral was either present or absent, we conducted infection experiments using the entomopathogenic fungus Metarhizium anisopliae (Ascomycota, Hypocreales) ${ }^{62}$. In brief, groups of three ant individuals were placed into an individual Petri dish with a ring of moist cotton. Then, each ant's propleural plate was inoculated with $0.5 \mu \mathrm{L}$ of Metarhizium spores of ca. $1.00 \times$ $10^{7}$ conidiospores $\mathrm{mL}^{-1}$ suspension $+0.01 \%$ Tween 20 by using a micropipette under a dissecting microscope. The experiment was replicated five times. The control for each replicate consisted of inoculating with a control solution of sterile, deionized water $+0.01 \%$ Tween $20^{63}$. The survival of ants (three individuals per sub-colony over five sub-colonies) was monitored every $24 \mathrm{~h}$ posttreatment for 6 days.

The Metarhizium anisopliae var. anisopliae strain was isolated from dead fungusgrowing ants in Gamboa, Panama, and grown on a pure medium of potato dextrose agar at room temperature until a full plate of spores was observed after around 7 days. The spores (conidia) were centrifuged, washed three times with sterile $0.05 \%$ Triton-X solution, and then harvested fresh for each infection experiment. For the infection experiments, spore suspensions were set up from recently sporulating cultures in a solution of sterile-deionized water containing $0.01 \%$ Tween 20 . Spore concentration was quantified using a hemocytometer and diluted to achieve a concentration of ca. $1.00 \times 10^{7}$ conidiospores $\mathrm{mL}^{-1}$.

Reporting summary. Further information on research design is available in the Nature Research Reporting Summary linked to this article.

\section{Data availability}

Source data files are provided on https://figshare.com/s/29b90a59a699bb33bf32. Each data set is provided as an Igor Pro experiment with file extension.pxp. All the relevant files for $\mathrm{C}$ and $\mathrm{O}$ spectra are zipped separately. Permits for collections and accessing genetic resources in Brazil were issued by SISBIO \#46555-5 and CNPq \#010936/2014-9. Costa Rican collecting permits were issued by the Comisión Institucional de Biodiversidad (Institutional Biodiversity Committee, University of Costa Rica; Resolutions \# 012 and 020; Material Transfer Agreement MTA VI-4307-2013) and authorized by La Selva Biological Station. Photos of Atta ants image and Apis bee image are used under a perpetual commercial license from Alexander L. Wild and Getty Images, respectively (Fig. 4). Xylotrechus beetle image provided with permission from the copyright holder, Jon Rapp (Fig. 4).

\section{Code availability}

The Igor Pro macros, called GG Macros, used to produce PIC maps are available free of charge on https://home.physics.wisc.edu/gilbert/software/. The code to measure the angular distances of $c$-axes in Fig. 2 is available on https://home.physics.wisc.edu/gilbert/ software/.

Received: 16 March 2020; Accepted: 15 October 2020; Published online: 24 November 2020

\section{References}

1. Knoll, A. H. Biomineralization and evolutionary history. Rev. Mineral. Geochem. 54, 329-356 (2003).

2. Eder, M., Amini, S. \& Fratzl, P. Biological composites-complex structures for functional diversity. Science 362, 543-547 (2018).

3. Sperling, E. A. et al. Oxygen, ecology, and the Cambrian radiation of animals. Proc. Natl Acad. Sci. USA 110, 13446-13451 (2013).

4. Gilbert, P. U. P. A. et al. Biomineralization by particle attachment in early animals. Proc. Natl Acad. Sci. USA 116, 17659-17665 (2019).

5. Gilbert, P. U. P. A., Abrecht, M. \& Frazer, B. H. The organic-mineral interface in biominerals. Mol. Geomicrobiol. 59, 157-185 (2018).

6. Bengtson, S. Early Life on Earth. Nobel Symposium No. 84. (ed. Bengtson, S.) 412-425 (Columbia University Press, New York, 1994).

7. Sanderson, K. Artificial armour. Nature 519, S14-S15 (2015).

8. Mass, T. et al. Amorphous calcium carbonate particles form coral skeletons. Proc. Natl Acad. Sci. USA 114, E7670-E7678 (2017).

9. DeVol, R. T. et al. Nanoscale transforming mineral phases in fresh nacre. $J$. Am. Chem. Soc. 137, 13325-13333 (2015).

10. Weaver, J. C. et al. The stomatopod dactyl club: a formidable damage-tolerant biological hammer. Science 336, 1275-1280 (2012).

11. Politi, Y., Arad, T., Klein, E. \& Addadi, L. Sea urchin spine calcite forms via a transient amorphous calcium carbonate phase. Science 306, 1161-1165 (2004).

12. Li, L. et al. Multifunctionality of chiton biomineralized armor with an integrated visual system. Science 350, 952-956 (2015).

13. Aizenberg, J., Tkachenko, A., Weiner, S., Addadi, L. \& Hendler, G. Calcitic microlenses as part of the photoreceptor system in brittlestars. Nature 412, 819 (2001).

14. Killian, C. E. et al. Self-sharpening mechanism of the sea urchin tooth. $A d v$. Funct. Mater. 21, 682-690 (2011).

15. Ma, Y. et al. The grinding tip of the sea urchin tooth exhibits exquisite control over calcite crystal orientation and $\mathrm{Mg}$ distribution. Proc. Natl Acad. Sci. USA 106, 6048-6053 (2009).

16. Wang, R. Z., Addadi, L. \& Weiner, S. Design strategies of sea urchin teeth: Structure, composition and micromechanical relations to function. Philos. Trans. R. Soc. B Biol. Sci. 352, 469-480 (1997).

17. Polishchuk, I. et al. Coherently aligned nanoparticles within a biogenic single crystal: a biological prestressing strategy. Science 358, 1294-1298 (2017).

18. Morse, J. W., Wang, Q. \& Tsio, M. Y. Influences of temperature and Mg:Ca ratio on $\mathrm{CaCO}_{3}$ precipitates from seawater. Geology 25, 85-87 (1997).

19. Oakley, T. H., Wolfe, J. M., Lindgren, A. R. \& Zaharoff, A. K. Phylotranscriptomics to bring the understudied into the fold: monophyletic Ostracoda, fossil placement, and pancrustacean phylogeny. Mol. Biol. Evol. 30, 215-233 (2013)

20. Schultz, T. R. \& Brady, S. G. Major evolutionary transitions in ant agriculture. Proc. Natl Acad. Sci. USA 105, 5435-5440 (2008).

21. Li, H. et al. Convergent evolution of complex structures for ant-bacterial defensive symbiosis in fungus-farming ants. Proc. Natl Acad. Sci. USA 115, 10720-10725 (2018).

22. Pinto-Tomás, A. A. et al. Symbiotic nitrogen fixation in the fungus gardens of leaf-cutter ants. Science 326, 1120-1123 (2009).

23. Weber, N. A. Gardening Ants: The Attines (American Philosophical Society, Philadelphia, 1972).

24. Wetterer, J. K. Forager size and ecology of Acromyrmex coronatus and other leaf-cutting ants in Costa Rica. Oecologia 104, 409-415 (1995).

25. Bekkevold, D., Frydenberg, J. \& Boomsma, J. Multiple mating and facultative polygyny in the Panamanian leafcutter ant Acromyrmex echinatior. Behav. Ecol. Sociobiol. 46, 103-109 (1999).

26. Ferguson-Gow, H., Sumner, S., Bourke, A. F. G. \& Jones, K. E. Colony size predicts division of labour in attine ants. Proc. R. Soc. B 281, 20141411 (2014).

27. Currie, C. R., Poulsen, M., Mendenhall, J., Boomsma, J. J. \& Billen, J. Coevolved crypts and exocrine glands support mutualistic bacteria in fungusgrowing ants. Science 311, 81-83 (2006).

28. Currie, C. R., Scott, J. A., Summerbell, R. C. \& Malloch, D. Fungus-growing ants use antibiotic-producing bacteria to control garden parasites. Nature $\mathbf{3 9 8}$, 701-704 (1999).

29. Currie, C. R., Mueller, U. G. \& Malloch, D. The agricultural pathology of ant fungus gardens. Proc. Natl Acad. Sci. USA 96, 7998-8002 (1999).

30. Adams, R. M. M., Mueller, U. G., Schultz, T. R. \& Norden, B. Agro-predation: usurpation of attine fungus gardens by Megalomyrmex ants. Naturwissenschaften 87, 549-554 (2000).

31. Fowler, H. G. Field response of Acromyrmex crassispinus (forel) to aggression by Atta sexdens (linn.) and predation by Labidus praedator (fr. smith) (Hymenoptera: Formicidae). Aggress. Behav. 3, 385-391 (1977).

32. Vilela, E. F. \& Howse, P. E. Fire Ants and Leaf-Cutting Ants. Biology and Management (eds Lofgren, C. S. \& Vander Meer, R. K.) 159-171 (Westview Press. Boulder, CO, 1986). 
33. Schofield, R. M., Nesson, M. H. \& Richardson, K. A. Tooth hardness increases with zinc-content in mandibles of young adult leaf-cutter ants. Naturwissenschaften 89, 579-583 (2002).

34. Weber, N. A. Gardening Ants: The Attines (American Philosophical Society, Philadelphia, 1972).

35. Myers, C. E. et al. Exceptional preservation of organic matrix and shell microstructure in a Late Cretaceous Pinna fossil revealed by photoemission electron spectromicroscopy. Geology 46, 711-714 (2018).

36. Gilbert, P. U. P. A., Young, A. \& Coppersmith, S. N. Measurement of c-axis angular orientation in calcite $\left(\mathrm{CaCO}_{3}\right)$ nanocrystals using X-ray absorption spectroscopy. Proc. Natl Acad. Sci. USA 108, 11350-11355 (2011).

37. Metzler, R. A. et al. Polarization-dependent imaging contrast in abalone shells. Phys. Rev. B 77, 064110-1/9 (2008).

38. Cody, G. D. et al. Molecular signature of chitin-protein complex in Paleozoic arthropods. Geology 39, 255-258 (2011).

39. Kaznacheyev, K. et al. Innershell absorption spectroscopy of amino acids. J. Phys. Chem. A 106, 3153-3168 (2002).

40. Zhang, F., Xu, H., Konishi, H., Shelobolina, E. S. \& Roden, E. E. Polysaccharide-catalyzed nucleation and growth of disordered dolomite: a potential precursor of sedimentary dolomite. Am. Mineral. 97, 556-567 (2012).

41. Lippmann, F. Sedimentary Carbonate Minerals (Springer, New York, 1973).

42. Peeters, C., Molet, M., Lin, C. C. \& Billen, J. Evolution of cheaper workers in ants: a comparative study of exoskeleton thickness. Biol. J. Linn. Soc. 121, 556-563 (2017).

43. Hölldobler, B. \& Wilson, E. O. The Superorganism: The Beauty, Elegance, and Atrangeness of Insect Societies (WW Norton, New York, 2008).

44. Dijkstra, M. B. \& Boomsma, J. J. Gnamptogenys hartmani Wheeler (Ponerinae: Ectatommini): an agro-predator of Trachymyrmex and Sericomyrmex fungus-growing ants. Naturwissenschaften 90, 568-571 (2003).

45. Yang, L., Killian, C. E., Kunz, M., Tamura, N. \& Gilbert, P. U. P. A. Biomineral nanoparticles are space-filling. Nanoscale 3, 603-609 (2011).

46. Wood, R., Ivantsov, A. Y. \& Zhuravlev, A. Y. First macrobiota biomineralization was environmentally triggered. Proc. R. Soc. B 284, 20170059 (2017).

47. Nygaard, S. et al. Reciprocal genomic evolution in the ant-fungus agricultural symbiosis. Nat. Commun. 7, 1-9 (2016).

48. Diamond, J. M. \& Ordunio, D. Guns, Germs, and Steel (Books on Tape, 1999).

49. Sun, C. Y. et al. Spherulitic growth of coral skeletons and synthetic aragonite: nature's three-dimensional printing. ACS Nano 11, 6612-6622 (2017).

50. Gong, Y. U. et al. Phase transitions in biogenic amorphous calcium carbonate. Proc. Natl Acad. Sci. USA 109, 6088-6093 (2012).

51. De Stasio, G., Frazer, B. H., Gilbert, B., Richter, K. L. \& Valley, J. W. Compensation of charging in X-PEEM: a successful test on mineral inclusions in 4.4Ga old zircon. Ultramicroscopy 98, 57-62 (2003).

52. DeVol, R. T. et al. Oxygen spectroscopy and polarization-dependent imaging contrast (PIC)-mapping of calcium carbonate minerals and biominerals. J. Phys. Chem. B 118, 8449-8457 (2014).

53. Zou, Z. et al. A hydrated crystalline calcium carbonate phase: Calcium carbonate hemihydrate. Science 363, 396-400 (2019).

54. Macros, G. G. http://home.physics.wisc.edu/gilbert/software.htm (2019).

55. Pokroy, B. et al. Narrowly distributed crystal orientation in biomineral vaterite. Chem. Mater. 27, 6516-6523 (2015)

56. Stohr, J. NEXAFS Spectroscopy (Springer-Verlag, Berlin, 1992).

57. Madix, R. J., Solomon, J. L. \& Stohr, J. The orientation of the carbonate anion on $\operatorname{Ag}(110)$. Surf. Sci. 197, L253-L259 (1988).

58. Henderson, J. W. Jr., Ricker, R. D., Bidlingmeyer, B. A. \& Woodward, C. Rapid, Accurate, Sensitive and Reproducible HPLC Analysis of Amino Acids (Agilent Pub.\# 5980-1193E, 2000).

59. Amini, S., Tadayon, M., Idapalapati, S. \& Miserez, A. The role of quasiplasticity in the extreme contact damage tolerance of the stomatopod dactyl club. Nat. Mater. 14, 943-950 (2015)

60. Oliver, W. C. \& Pharr, G. M. An improved technique for determining hardness and elastic modulus using load and displacement sensing indentation experiments. J. Mater. Res. 7, 1564-1583 (1992).

61. Hölldobler, B. \& Wilson, E. O. The Ants (Harvard Univ. Press, Cambridge, MA, 1990).
62. Wang, C. \& Wang, S. Insect pathogenic fungi: genomics, molecular interactions, and genetic improvements. Annu. Rev. Entomol. 62, 73-90 (2017).

63. Wang, B., Kang, Q., Lu, Y., Bai, L. \& Wang, C. Unveiling the biosynthetic puzzle of destruxins in Metarhizium species. Proc. Natl Acad. Sci. USA 109 1287-1292 (2012)

64. Graf, D. L. \& Goldsmith, J. R. Some hydrothermal syntheses of dolomite and protodolomite. J. Geol. 64, 173-186 (1956).

\section{Acknowledgements}

We thank U. P. Agarwal and S. A. Ralph from U.S. Forest Products Laboratory for the Raman spectroscopy measurements; B. Schneider and R. Noll for expert help conducting SEM work; J. Morasch for assistance with nanoindentation measurements; E. Okonski for ant imaging and laboratory assistance; and R. J. Massey for assistance with the microtome. This work was primarily supported by the National Institutes of Health (NIH) Grant U19 TW009872-05, NIH Grant U19 AI109673 and the Department of Energy Great Lakes Bioenergy Research Center Office of Science Grant DE-FC0207ER64494 to C.R.C. P.U.P.A.G. acknowledges support from the U.S. Department of Energy, Office of Science, Office of Basic Energy Sciences, Chemical Sciences, Geosciences, and Biosciences Division, under Award DE-FG02-07ER15899, and NSF grant DMR-1603192. PEEM experiments were done at the Advanced Light Source, which is a DOE Office of Science User Facility supported by grant DE-AC02-05CH11231. T.R.S. is supported by the National Science Foundation award DEB 1654829 and DEB 1927224 H.X. and Y.F. is supported by the NASA Astrobiology Institute (NNA13AA94A) and S. W. Bailey Scholarship of the Department of Geoscience.

\section{Author contributions}

Study design: H.L., C.-Y.S., P.U.P.A.G., and C.R.C. Experimental design and supervision H.L., C.-Y.S., T.R.S., P.U.P.A.G., and C.R.C. Data collection and analysis: H.L., C.-Y.S. Y.F., C.M.C., H.X., A.J., J.S.-C., R.Z., H.A.B., J.H.F., D.R.A., T.R.S., P.U.P.A.G., and C.R.C. Initial draft: H.L., C.R.C., T.R.S. C.-Y.S., and P.U.P.A.G. Final version: all authors.

\section{Competing interests}

The authors declare no competing interests.

\section{Additional information}

Supplementary information is available for this paper at https://doi.org/10.1038/s41467 020-19566-3.

Correspondence and requests for materials should be addressed to P.U.P.A.G. or C.R.C.

Peer review information Nature Communications thanks Charissa de Bekker and the other, anonymous, reviewers for their contribution to the peer review of this work. Peer reviewer reports are available.

Reprints and permission information is available at http://www.nature.com/reprints

Publisher's note Springer Nature remains neutral with regard to jurisdictional claims in published maps and institutional affiliations.

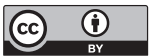

Open Access This article is licensed under a Creative Commons Attribution 4.0 International License, which permits use, sharing, adaptation, distribution and reproduction in any medium or format, as long as you give appropriate credit to the original author(s) and the source, provide a link to the Creative Commons license, and indicate if changes were made. The images or other third party material in this article are included in the article's Creative Commons license, unless indicated otherwise in a credit line to the material. If material is not included in the article's Creative Commons license and your intended use is not permitted by statutory regulation or exceeds the permitted use, you will need to obtain permission directly from the copyright holder. To view a copy of this license, visit http://creativecommons.org/ licenses/by/4.0/.

(c) The Author(s) 2020 